УДК 330.1

DOI 10.18101/2304-4446-2020-2-9-14

\title{
РОЛЬ ОБРАЗОВАНИЯ В ЭКОНОМИЧЕСКОМ РАЗВИТИИ
}

\author{
(C) Пашахина Екатерина Александровна \\ аспирант, \\ Национальный исследовательский Томский государственный университет \\ Россия, 634050, г. Томск, пр. Ленина, 36 \\ E-mail: ekaterinapashaxina@gmail.com
}

Образование является основой развития, на которой строится значительная часть нашего экономического и социального благосостояния. Также образование является ключом к повышению экономической эффективности и социальной ответственности. Повышая ценность и эффективность труда, оно помогает бедным слоям населения улучшить свое материальное положение. Это повышает общую производительность и интеллектуальную гибкость рабочей силы. Образование помогает обеспечить конкурентоспособность страны на мировых рынках, для которых сейчас характерны меняющиеся технологии и методы производства. Образовательный процесс, начинающийся на ранних этапах жизненного пути ребенка, в значительной степени способствует формированию контактов с представителями различных социальных групп и содействует межличностной терпимости. В статье рассмотрены различные точки зрения экономистов (как теоретиков, так и практиков) на роль образования в экономическом развитии.

Ключевые слова: развитие человеческого потенциала; экономический рост; производительность труда; образование; технологии; нищета; торговля; здравоохранение.

\section{Для цитирования}

Пашахина Е. А. Роль образования в экономическом развитии // Вестник Бурятского государственного университета. Экономика и менеджмент. 2020. № 2. С. 9-14.

1. Важность образования в экономическом развитии

Образование можно определить как запас навыков, компетенций и других повышающих производительность характеристик. В целом образование как важнейший компонент человеческого капитала страны повышает эффективность каждого отдельного работника и помогает экономическим системам продвигаться вверх по цепочке создания стоимости, выходя за рамки ручных задач или простых производственных процессов. Человеческий капитал долгое время считался наиболее отличительной чертой экономической системы и только сейчас благодаря научным изысканиям стал относиться к эффективным методам производства (сначала в странах Европы, а затем постепенно в других странах). В двадцатом веке образование, навыки и приобретенные знания стали решающими детерминантами человека и национальной производительности. Можно назвать двадцатый век «эпохой человеческого капитала», в том смысле, что основным детерминантом уровня жизни страны стала необходимость развивать и использовать навыки и знание, а также содействовать здоровью и образованности большинства населения.

Последние десятилетия, например в странах Ближнего Востока, происходит расширение доступа к базовому образованию. Многие страны в настоящее время 
приступили к дальнейшему расширению доступности к среднему и высшему образованию и значительному повышению качества образования на всех уровнях. По мере того как все большее число обучающихся получает базовое образование, повышается их спрос на высшее образование. Образование девочек и женщин, вероятно, является наиболее эффективным вложением средств, которое может сделать развивающаяся страна, независимо от того, работают ли женщины вне дома или нет.

Образование играет ключевую роль в семье, так как с его помощью люди могут добиваться невероятных высот, строить карьеру, быть востребованными специалистами. От конкуренции и глобализации на мировых рынках образовательных услуг зависит совершенствование человеческого капитала. Для обеспечения более высокого уровня образования граждан потребуется набор новых образовательных программ, усовершенствованных педагогических методик и научных методов, которые содействуют формированию когнитивных навыков более высокого порядка.

Без значительных инвестиций в человеческий капитал ни одна страна не добилась бы экономического развития. Во многих исследованиях рассматривают отдачу от различных форм накопления человеческого капитала: базовое образование, научные исследования, профессиональная подготовка, обучение на практике и развитие навыков. Образование имеет значение в распределении: если доступ к нему не одинаков, как правило, это негативно сказывается на доходах на душу населения в большинстве стран. Распределение человеческого капитала и использование соответствующих функциональных форм влияют на средний уровень образования и на доход на душу населения, в то время как невыполнение этих требований приводит к негативным последствиям.

В более ранних неоклассических моделях образование не считалось важным фактором производства и, следовательно, не включалось в модели роста. В 1960-х гг. растущие эмпирические данные стимулировали «революцию инвестиций человека в экономическую мысль». Теодор Шульц (1961) в своих исследованиях рассматривал экономический рост как функцию от уровня образования. В исследованиях Гэри Стэнли Беккера (1964) [1] и Джейкоба Минсера (1974) [6] рассматривалось влияние образования на заработки или предполагаемый уровень прибыли частного сектора. В ходе исследования Джорджа Псахаропулоса в 1984 г. экономического роста, охватывающего 29 развивающихся стран, были получены оценки вклада образования в экономический рост в пределах от менее 1 процента в Мексике до 23 процентов в Гане.

2. Образование и производительность

В любой стране образование является одним из основных факторов состава и роста производства и экспорта, оно является частью системы, которая эффективно заимствует иностранную технологию. Если рассмотреть социальную сферу, то начальное и среднее образование повышает производительность труда рабочих, а среднее образование является также важнейшим элементом развития ключевых институтов и финансовой системы. Профессиональное образование же способствует приобретению навыков и управленческого потенциала, высшее образование - развитию фундаментальной науки, что является значимым для экономического роста. 
На микро- и макроуровне эмпирические данные демонстрируют эти возможности. Многочисленные исследования на микроуровне показывают, что увеличение заработной платы связано с дополнительными годами обучения [8, с. 133$144]$.

Уровень образования работников, занятых в сельском хозяйстве, оказывает положительное влияние на производительность труда. Например, в Непале фермеры, которые завершили школьное обучение на уровне не менее семи лет, повысили продуктивность в пшенице более чем на 25\%, а в рисе - на $13 \%$. Образование является важным фактором развития технологического потенциала и технических изменений в промышленности.

Само по себе образование, конечно, не может трансформировать экономику. Объем и качество инвестиций, как внутренних, так и иностранных, а также общая политическая обстановка являются другими важными факторами, определяющими экономические показатели. Однако уровень развития человеческого потенциала также влияет на эти факторы. Качество разработки политики и инвестиционных решений неизбежно зависит от уровня образованности руководителей. Вероятнее всего, объем внутренних и иностранных инвестиций будет больше, когда уровень человеческого капитала будет более значительным. Для макроуровня «новые теории роста» нацелены на эндогенизацию технического прогресса путем включения некоторых из этих же эффектов, уделяя особое внимание образованию, а также обучению и НИОКР. По мнению Роберта Эмерсона Лукаса (1998) [7], например, чем выше уровень образованности рабочей силы, тем выше общая производительность капитала, потому что более образованные люди более склонны к инновациям и, таким образом, влияют на производительность труда каждого человека.

В других моделях аналогичный внешний эффект возникает по мере того, как повышение уровня образованности отдельных лиц повышает собственную производительность и производительность других людей. В результате чего общая производительность возрастает по мере повышения среднего уровня образованности [10, с. 149-187]. Образование влияет на характер и рост экспорта, которое, в свою очередь, влияет на совокупные темпы роста. В развитых странах образование и навыки рабочей силы влияют на структуру ее торговли. На современных фабриках «неквалифицированные» работники нуждаются в навыках, которые приобретаются в начальной и средней школе первой ступени.

3. Образование и доход

Образование положительно влияет не только на обеспечение равенства доходов, но и на более высокий темп экономического роста. С помощью образования люди с низким уровнем дохода могут реализовать более эффективные стратегии поведения. Исследования в странах Латинской Америки в 80-е гг. ХХ в. взаимосвязи между школьным образованием, неравенством в доходах и нищетой показали, что различие в доходах работников объясняется различиями в уровне школьного образования, а значит, образование является переменной, влияющей на равенство доходов [9]. Исследование факторов, которые влияют на распределение доходов, показало значимость вторичного образования [3]. Образование влияет на доходы на душу населения за счет изменения знаменателя, т. е. роста числа жителей. Исследования, проведенные в африканских странах в середине 
80-х гг. XX в., показали отрицательное соотношение почти во всех странах между женщинами, имеющими начальное школьное образование, и рождаемостью. Страны, такие как Кения, Ботсвана и Зимбабве, добились успеха с точки зрения снижения рождаемости и показателей детской смертности, имея самый высокий уровень женского школьного образования.

4. Образование и семья

Откуда берется человеческий капитал? Что представляет собой успешное инвестирование в человеческий капитал как на индивидуальном, так и на национальном уровне? Человеческий капитал (образование и состояние здоровья населения) играет значительную роль в экономическом развитии страны. Лучшее образование приводит не только к более высокому личному доходу, но и является также необходимым (хотя не всегда достаточным) условием для долгосрочного экономического роста. Именно семья старается любыми ресурсами повышать образованность своих детей. Семьи принимают самые разные решения. Одно из них заключается в том, чтобы ответить на вопрос - иметь ли больше детей или меньше детей? Другие семьи пытаются сделать больше для единственного ребенка. По мере повышения уровня развитости стран тренд очень сильно смещается в сторону последних. Каждая нация, которая обеспечила стремительное развитие своего государства, реализовала эту практику за удивительно короткий временной период. Так, на Тайване рождаемость ниже, чем в США. Снижение рождаемости характеризует также Гонконг, Мексику и Польшу. В развитой части Турции среднее число детей в семьях ниже, чем в менее развитой части Турции. Это связано с уровнем образованности семей: в среднем образованные семьи имеют от 1 до 4 детей, а необразованные - более 5 детей. Таким образом, для снижения рождаемости и неравенства между этими регионами Турции необходимо уделять больше внимания образованию.

Повышение уровня образования родителей, преимущественно матерей, как правило, способствует улучшению обращения с детьми. Когда образование родителей выше среднего, разрыв между образованием сыновей и дочерей снижается. Обычно такие родители больше вкладывают в свое здоровье и здоровье своих детей. Как показывают исследования, образование является наиболее важным персональным фактором, определяющим состояние здоровья и продолжительность жизни человека. Связь между образованием и здоровьем, продолжительностью жизни связана с причинно-следственной связью в обоих направлениях, поскольку высокий уровень здоровья и снижение смертности приводят к увеличению инвестиций в образование и другие виды человеческого капитала. При увеличении ожидаемого количества рабочего времени доходность этих инвестиций возрастает.

\section{5. Образование и торговля}

Некоторые страны успешно объединили открытость и инвестиции в обучение и образование, сформировав добродетельный круг: открытость создает спрос на образование, а обучение и образование делают экспортный сектор страны более конкурентоспособным. Накопление знаний влияет на показатели торговли и конкурентоспособность страны. Торговля, в свою очередь, способствует накоплению знаний, особенно за счет импорта. Роберт Лукас (1998) отмечает, что для поддержания любого рода накопления знаний страна должна быть ориентирова- 
на на внешний рынок и быть значимым экспортером образовательных услуг. Торговля сама по себе не может быть локомотивом роста, а скорее должна содействовать какому-то механизму, например формированию человеческого капитала. Исследование Всемирного банка показало, что темпы экономического роста в выборке 60 развивающихся стран в 1965-1987 гг. были особенно высокими в сочетании с высоким уровнем образованности населения и макроэкономической стабильностью и открытостью. Таким образом, влияние торговой открытости на долгосрочный рост зависит от того, насколько хорошо люди способны поглощать и использовать информацию и технологии, предоставляемые через торговлю и иностранные инвестиции. Широко признается, что для адаптации к условиям более сильной конкуренции и к миру, подчеркивающему роль информации, знаний и навыков, страны с развитой экономикой должны постоянно повышать общее качество своей рабочей силы.

\section{Заключение}

Образование играет важную роль в экономическом развитии и оказывает существенное влияние на производительность труда, торговлю, технологии, здравоохранение, распределение доходов и структуру семьи. Образование помогает развивать качественный уровень домохозяйства, формирует в семье, в людях личностные качества, такие как самодисциплина, целеустремленность, воспитанность, толерантность, коммуникабельность, тяга к новым источникам информации и многое другое. Соответственно, выработанные качества могут помочь человеку лучше адаптироваться в социальной среде, высказывая свои мысли и точку зрения, найти единомышленников, а также приобрести значимый статус в обществе. Именно образование формирует человеческий капитал. Семьи, которые хотят развиваться, меняться и стать ячейкой информационного общества, должны больше инвестировать в образование, потому что они не могут выжить и развиваться в течение долгих лет с нынешними знаниями. При этом жизненно важно использовать полученные знания для достижения политических, социальных и экономических целей. Полученные знания не следует оставлять на полке, однако они должны использоваться для реализации социальных целей. В это время можно будет пройти долгий путь к развитию и изменениям в семье. Сообщества, которые хотят развиваться и меняться, должны производить новые знания и постоянно следовать новинкам. В современном мире образование является главным фактором в успехе компаний на мировых рынках, влияет на экономический рост и содействует увеличению научно-технического потенциала страны. Уровень образования и накопленные знания определяют преимущества в конкурентной борьбе.

\section{Литература}

1. Беккер Г. С. Преступление и наказание. Экономический подход / ред. Г. С. Беккер, В. М. Ландес. Нью-Йорк, 1974. 64 с.

2. Беккер Г. С. Человеческое поведение: экономический подход. М.: ГУ ВШЭ, 2003. 672 c. ISBN 5-7598-0173-2

3. Бургиньон Ф. Влияние экономического роста на социальные структуры / ред. Ф. Агрионе, С. Н. Дюрлауф // Справочник экономического роста, 1В. Амстердам: Elsevier, 2005. C. 1701-1748. ISBN 9-7804-4452-0432. 
4. Бургиньон Ф., Моррисон С. Распределение доходов, развитие и внешняя торговля: Анализ // Европейский экономический обзор. 1990. Т. 34, № 6. Р. 1113-1132.

5. Гроссман Д. М., Хелпман Э. Сравнительные преимущества и долгосрочный рост. Рабочий документ № 2809. Кембридж, Mass.: NBER, январь 1989.850 с.

6. Минсер Д. Прогресс в области анализа человеческого капитала при распределении доходов. Нью-Йорк, 1974. 202 с.

7. Лукас Р., Стокей Н. Л., Прескотт Э. С. Рекурсивные методы в экономической динамике. Гарвардский университет Пресс, 1989. 157 с.

8. Псахаропулос Д., Патринос Г. Борьба с нищетой среди коренного населения Латинской Америки: новые задачи системы образования // Перспективы. 1996. Т. ХХХ, № 4. C. 133-144.

9. Псахаропулос Д. Вклад образования в экономический рост. Международные сравнения // Экономика образования. 1999. № 1. С. 62-71.

10. Роберто П. Рост, распределение доходов и демократия: О чем говорят данные // Рост. 1996. T. 1, № 2. С. 149-187.

\title{
ROLE OF EDUCATION IN ECONOMIC DEVELOPMENT
}

\author{
Ekaterina A. Pashakhina \\ Research Assistant, \\ National Research Tomsk State University \\ 36 Lenina Prospect, Tomsk 634050, Russia \\ E-mail: ekaterinapashaxina@gmail.com
}

Education is the fundamental factor of economic development and social well-being. Also, it is the key to improving economic efficiency and social responsibility. By increasing the value and effectiveness of labour, education helps the poor to improve their wealth status. This increases overall productivity and intelligent flexibility of workforce. Education work towards the country's competitiveness in the world markets, which nowadays are characterized by changing technology and production methods. Educational process that begins in the early childhood greatly contributes to expansion of contacts with representatives of various social groups and promotes interpersonal tolerance. The article considers the different views of economists (both theorists and practitioners) on the role of education in economic development.

Keywords: human development; economic growth; labour productiveness; education; technology; poverty; trade; public health services. 